accurate representation of physical signs can be made in all instances, because the size and shape of the chest varies so much in different individuals.

The stamps can be obtained from the makers, Messrs. R. C. Perry and Co., engravers and stamp makers, 14, Cannon Street, Manchester; price 18s. $6 \mathrm{~d}$.

\section{THE PRESENT EXAMINATION SYSTEM.}

BY JOHN STRUTHERS, M.D., LL.D.,

Emeritus Professor of Anatomy in the University of Aberdeen.

Тнк large and increasing proportion of rejections is at last attracting attention. When we reflect on the fact that rejections have run up to some 30 per cent. of the examinedtwice what the proportion was twenty years ago, three times what it was thirty years ago-it goes without saying that there is something wrong in the present system of examination, or in the teaching, or in their relation to each other. It is not the student's blame. He is not less industrious than when I knew him twenty, thirty, or fifty years ago. The views of one who has had experience in teaching and in examining, and who is free to speak, may perhaps be of some use at the present time.

I believe that the present system of examination fails seriously to secure the desired results, and that it is injurious to good medical education. The education is the main thing, but the education is regulated by the examinations, more and more so as these are multiplied. Using the word "cramming" deliberately, I hold that the present examination system leads to and rewards cramming; that it does so $(a)$ by the multiplication of examinations, and $(b)$ by wrong method at the examinations.

(a) I am not here suggesting any departure from the general recommendation by the General Medical Council, and adopted by the various examining bodies, that there should, in the new five-year course, be four examinations. The evil lies in the Boards having allowed subdivision of these four examinations, and in intervals between the four examinations not having been prescribed. The result is that the candidate may take the examinations bit by bit, one subject at a time, for which he crams.

Thus, under the regulations of the Conjoint Boards, the first examination may be taken in England in four parts at different times, in Scotland in three parts; the third examination at both Boards in three parts; and the fourth examination in four parts at the Scotch Board. For each of these bit-by-bit examinations the student crams up, and the teaching has to be shaped accordingly. Student life consists, not in studying to know his profession, but in the distractions of preparing for this or that bit of examination, and the teacher has too commonly fallen to the rank of a grinder.

The evil of the bit-by-bit system comes out most manifestly in the examination in medicine, surgery, and midwifery being allowed to be taken in three parts at different times. Of what real value is the kind of surgical or medical or obstetric knowledge that the candidate could not carry in his head or prove with his hands beyond the three or the six or more months that may intervene between the first, the second, and the third bits of the examination? It is the examination for the general practitioner, and the aim of the examination should be to test the man's whole fitness to practise his profession. The permission to take the preliminary examination bit by bit led to such abuse that we had to put a summary stop to it and require the whole to be passed at one time. The four examinations already give as much subdivision to the professional examination as ought to be allowed. I would say they are one too many unless the fourth is to be strictly clinical. It belongs to the schools to see that their students take the classes in the proper order, and to each teacher to see that his students are working. The object in the examinations held by a licensing board should be to test, not what the student can cram, but. after due time allowed for study, to test what he has retained.

While thus criticising the regulations of the London Conjoint Board in regard to the bit-by-bit system, towards which they appear to stand in loco parentis, I would ask the con- sideration of other boards to two admirable rules in these regulations : 1. Intervals are prescribed between the four ex aminations; six months between the last bit of the first examination and admission to the second; two years between the second and third examinations; and a year between the third and final examination. 2. This final examination is exclusively a clinical examination in medicine and surgery, and in midwifery and gynæcology if that subject has not been taken with the previous general examination in medicine and surgery and allied subjects at the end of the fourth year. It is the only board, so far as I am aware, that has ensured the carrying out of the recommendation of the General Medical Council that the fifth year should be devoted to clinical work at hospitals or dispensaries, or, it may be, half of it spent in pupilage with a practitioner. Except in regard to a weakness in securing efficient teaching in the auxiliary sciences (at present a question for the General Medical Council to deal with), and except in regard to the bitby-bit system, which may be easily dropped, I would hold up the regulations of the English Conjoint Board as typical ; as on the whole the best we have in the United Kingdom, those of no university excepted, for producing the best article for admission to the medical profession. The special points of merit are the compulsory intervals, and, by the last of these, securing the fifth year exclusively for practical work.

(b) Still more injurious to education and futile in results I hold to be the present method of conducting the examinations. Far too much importance is attached to the written part. What we wish is real knowledge, not merely word knowledge. Written examination, so far as I could learn, is not employed in medical examinations in France or in Germany, and is of comparatively modern use in this country. It has grown vastly at some boards, and much might be said as to its baneful antecedent influence on the teaching. Long experience in teaching and in examining at various boards has taught me to attach little weight to written examination. It has the seductive recommendation of saving the time of the examiners. I would continue it for that purpose in a different sense, using it as eliminatory in cases in which it affords abundant evidence that it would be a waste of the time of the examiners to send the candidate on to the oral examination. The practice of taking a mean, allowing good marks for the paper to make up for bad marks at the oral and practical, ought to cease. 'The pass-mark should be required to be reached at the oral and practical part or parts.

But what I desire to insist on most of all is, that the socalled oral examination ought to be more demonstrative or practical, and have more time allowed for it than is customary at nearly all the boards. The modern oral examinations appear to be suffering from the same incompatibilities as the modern teaching. Under the influence of the modern wave, the demand for real instead of word knowledge, there have been added so-called practical classes (some of them not very practical), but without abatement of the over lecturing. The student is pulled about from class to class in distraction, but, on the whole, finds his safety in looking to the old. So, in the oral examinations, there has been the introduction of the objective and the practical to some extent here and there, sometimes real, sometimes only in appearance, but the new wine has not been in quantity sufficient to burst the old bottles. Examiners trained in the old way go on mainly in the old way, and, still more disappointing, the young examiner too, fresh from the cramming school, takes the talking way. What I plead for is an entire reform in method at the oral examinations, for what may be called the laboratary and bedside method all round, and for ample time to be given to it.

If the regulations and recommendations made by the General Medical Council in enacting and planning in 1890 the new five-year course are looked at, it will be seen that, whether in regard to education or examination, what I plead for is arranged for and foreshadowed, leaving it to the examining boards to fill up the framework. Thirty-five long years have come and gone since the Medical Act of 1858 was passed to enable us to produce persons having "the requisite knowledge and skill for the efficient practice of their profession." and yet we are far from having found a perfect way of reaching that goal. Some think we never shall till some kind of State examination is set up. Life is full of disillusions, 
and perhaps we were wrong in not taking that view years ago-a State examination, either of a practical kind, or also of the nature of a general review examination. I, for one, have no wish to see a King Stork swallow up all our examining bodies, but less of King Log, in the shape of more power to the General Medical Council, is desirable. But that would mean a Medical Bill, and no man who lived through the thirty years' war of the Medical Bills can desire to live to see another. Is it too much to hope that at least the three Conjoint Boards with their flexible machinery will now set themselves in earnest to carry out to the full these behests of the General Medical Council?

Our aim in regard to education should be to promote practical study in all the branches, training the rising youth to observe Nature for themselves, Nature in the laboratories, the dissecting room, the post-mortem room, and at the bedside, and to cultivate the open mind for progress that is sure to be made in our ever-advancing sciences and art. Our aim in regard to the indispensable evil of examinations should be to test such knowledge.

Edinburgh, Nov. 18th, 1893.

\section{THE ALLEGED INCREASE OF INSANITY.}

BY HENRY RAYNER, M.D.

Lecturer on Mental Diseases at St. Thomas's Hospital.

THE great extension of asylums in recent years has made the question of the increase of insanity of interest both to the specialist and the layman, with the result that very widely divergent opinions have been expressed. The Commissioner in Lunacy, in their latest annual reports, have repeatedly suggested that the increase in the number of the recorded insane was more apparent than real. Mr. Noel Humphreys also refused to admit that the then available statistics gave any conclusive evidence of an actual increase in the rate of occurring insanity. More recently Mr. Corbet, in the Fort nightly Review, saw reason to believe that insanity was advancing by leaps and bounds. Dr. Hack Tuke, on the contrary, in treating of the same subject at the annual meeting of the British Medical Association in the present year, arrived at very much the same conclusion as Mr. Humphreys, and Dr. Cobbold has also quite recently endorsed this view

The primary admissions to asylums, if accurate records had heen kept, would at once have solved this question, but unfortunately such statistics as exist are unreliable, so that at present conclusions on the subject can only be drawn indirectly from other facts and figures. The only statistics (for reasons too complex to be briefly stated) which can be relied on for this purpose are those which extend from 1871 to the present date.

The census statistics of insanity for England and Wales analysed in recent articles in this JounNAL have yielded three clear and definite facts : $(a)$ that in the last two decades there has been a progressive diminution in the number of mentally afflicted under the age of 25 years; $(b)$ that there has been an inconsiderable increase between the ages of 25 and $45 ;$ and $(c)$ that practically all the excess of increase has been in persons above the age of 45 years. These results of the recent census, if reliable, would almost limit the question to the inquiry into the reason of this greater excess of cases above the age of 45 .

The tendency of census returns is, by all experience, towards greater accuracy, and although there are doubtless still a certain number of mental cases-especially under the :age of 5-not recorded in the census tables, yet the probability is in favour of this number being less at the late than in the earlier returns. This should have produced a statistical increase, the absence of which emphasises the recorded decrease in the first twenty-five years of life.

A further increase at those ages should have resulted from the great extension of institutional care. Thus, the census of 1871 showed that under the age of 25 there were 4,025 mentally unsound persons in institutions and 10,415 out of them, but in 1891 there were 8,583 in institutions and only ' 7,799 out. The diminution between the ages of 15 and 25 -was from 2.30 per 10,000 of population in 1871 to 2.16 in 1881 and 2.00 in 1891 ; but it is probably even larger than this, since it has occurred in spite of the increase which might have been expected from the greater accuracy of census returns and from the larger survivorship from the doubled numbers in institutions.

The decrease of insanity in the population in the first twenty-five years of life, if satisfactorily proved, would go far to convince those who have actual experience of the insane that this must correspond to a diminution in the total production of mental disease. The tendency to increasing degeneration in the families of the insane, resulting in later generations in mental defect, either congenital or developing in early life, has been pointed out by many observers (Maudsley, Baillarger, etc.), and is a well-established fact. If, therefore, there has been a diminution in the early decades of life, this must correspond to, and be the result of, a lessening of hereditary influences, these being by far the largest factors of causation at these ages, which must operate not only in the early, but also in the later, periods of life.

Hereditary causes, in the tables of the Commissioners in Lunacy, do not, however, bear evidence of any diminution; but it must be remembered that these returns are yearly receiving greater attention, that the means of obtaining information of this kind is steadily increasing, and that at all times the estimates of heredity by different observers have varied as widely as from 30 to 60 per cent.

The lessening of hereditary influences by the restraint in asylums of so much larger a proportion of the insane population is probable, and has long been predicted as a possible result.

The slight excess of recorded insanity between the ages of 25 and 45 is of even greater significance than the diminution in the earlier decades. Mentally afflicted persons àt these ages (and, indeed, at all ages) have been yearly moro and more brought into institutions, from greater confidence in their management, and from the greatly increased comfort therein obtained, but also from the great growth of the urban population (among whom there is much more difficulty in retaining such cases in home life), and, as Dr. Howden, with others, has pointed out, from the changed conditions of industrial life (work being so much more aggregated in factories, etc.), also rendering impossible the home supervision of imbeciles.

These causes, together with an increased keenness, both medical and lay, in the recognition of mental disorder, and a heightened standard of mental fitness from better education, have probably led to more exhaustive registration in the census returns. The influence of these causes is shown hy a table prepared by Mr. Humphreys, from which it appears that the proportion of cases disclosed by the census, but unknown to the Commissioners in Lunacy, is as high as 34 per cent. of the insane population of some agricultural counties, while it falls to 13 per cent. in those having large urban or manufacturing centres.

The asylum population (whatever the causes) has increased since 1871 by about 30,000 , and if the facts relating to increased survivorship under asylum treatment have any cogency, this (survivorship) would by itself account for the small advance in the census numbers of the insane under the age of 45 , from 2.24 per 1,000 of population in 1871 to 2.26 per 10,000 in 1891 , without resorting to any theory of actual increase.

This period of life (from 25 to 45), the period of the greatest activity both physiological and social, the period during which the most important causes of insanity have fullest play, and the period of the incidence of nine-tenths of that extensive disease, general paralysis, would certainly be expected to yield conclusive proof of a definite increase of mental disorder, did any such exist. If, on the contrary. it yields evidence of a doubtful character, the conclusion is inevitable that the patent causes of insanity acting during this period of life are also not in any greatly increased activity.

If heredity is diminished in the early decades, and the most potent direct causes not increased during the most active period of life, what are the new factors that lead to a greater development of insanity after the age of 45 , if there is any such? Is it, indeed, increase, or mere accumulation from greater survivorship and other causes?

That there is a very greatly increased survivorship of persons mentally affected when cared for in institution, and ispecially in the asylums, cannot be doubted. 